Boise State University

ScholarWorks

Educational Technology Faculty Publications and Presentations

$11-2018$

\title{
Knowledge-Sharing and Potential Virtual Communities of Practice in the U.S. Coast Guard's Afloat Community: A Qualitative Pilot Study
}

Lisa Rodman

Boise State University

Jesús Trespalacios

Boise State University, jesustrespalacios@boisestate.edu

Follow this and additional works at: https://scholarworks.boisestate.edu/edtech_facpubs

Part of the Instructional Media Design Commons

\section{Publication Information}

Rodman, Lisa and Trespalacios, Jesús. (2018). "Knowledge-Sharing and Potential Virtual Communities of Practice in the U.S. Coast Guard's Afloat Community: A Qualitative Pilot Study". TechTrends, 62(6), 602-611. https://doi.org/10.1007/s11528-018-0291-8 
This is an author-produced, peer-reviewed version of this article. The final, definitive version of this document can be found online at

TechTrends, published by Springer. Copyright restrictions may apply. doi: 10.1007/s11528-018-0291-8

\title{
Knowledge-Sharing and Potential Virtual Communities of Practice in the U.S. Coast Guard's Afloat Community: A Qualitative Pilot Study
}

\author{
Lisa Rodman \\ Boise State University \\ Jesús Trespalacios \\ Boise State University
}

Ethical Approval All procedures performed in studies involving human participants were in accordance with the ethical standards of the institutional and/or national research committee and with the 1964 Helsinki declaration and its later amendments or comparable ethical standards.

Informed Consent Informed consent was obtained from all individual participants included in the study.

Conflict of Interest: The authors declare that they have no conflict of interest.

Acknowledgements: This article is not an official U.S. Government or U.S. Coast Guard article. The views expressed herein are those of the authors and are not official policy statements nor intended to result in official policy.

Keywords: knowledge-sharing, professional development, trust, virtual communities of practice

\begin{abstract}
Virtual communities of Practice (VCoP) offer a flexible option for professional development that may be employed by geographically dispersed communities. Due to unique and dynamic operational demands and a reduced training budget, the United States Coast Guard's (USCG) afloat community has limited opportunity for formal professional development, but alternative learning options have yet to be formally researched. This qualitative pilot study employed purposeful sampling to conduct 6 one- on-one interviews of afloat members with varying degrees of afloat experience and total time in service. The interviews were used to elucidate the knowledge-sharing culture of the afloat community, including the degree to which afloat members are willing to exchange knowledge and how trust, reciprocity, and disposition towards online learning influence this exchange. Interviews were digitally recorded and manually transcribed. Emergent themes included willingness and desire to share knowledge, concerns regarding service reputation, provisions for anonymity, and altruistic information exchange.
\end{abstract}

Due to unique and dynamic operational demands and a reduced training budget, the United States Coast Guard's (USCG) afloat community has limited opportunity for formal professional development and training. High personnel transfer rates also challenge knowledge management and organizational stability in the afloat community. Similar organizational challenges precipitated innovative performance support interventions in various operational sectors of the USCG (Rossett and Mohr, 2004). The pursuit of more flexible professional development options for the afloat community warrants additional research.

Virtual Communities of Practice (VCoP) offer an accessible and potentially cost- effective mechanism for professional development and knowledge exchange (Kok, 2010). The afloat community's use of a VCoP may significantly reduce travel costs and members' time away from their field units, thus maintaining operational readiness. Virtual forums also offer flexible response time and rapid information exchange (Ho et al., 2010). These efficiencies are in direct alignment with the military's desire for consistent training and enhanced proficiency (Salas, Milham, \& Bowers, 2003). Although the potential for VCoP to efficiently augment existing professional development and training 
This is an author-produced, peer-reviewed version of this article. The final, definitive version of this document can be found online at TechTrends, published by Springer. Copyright restrictions may apply. doi: 10.1007/s11528-018-0291-8

opportunities is significant, a greater understanding of the knowledge-sharing culture of the USCG's afloat community is necessary before attempting this intervention. Current awareness of knowledge-sharing within the afloat community is limited to anecdotal knowledge as formal research has yet to be conducted.

This study aims to elucidate the knowledge-sharing culture of the afloat community, including the degree to which afloat members are willing to exchange knowledge and how trust, reciprocity, and disposition towards online learning influence this exchange. Through this comparison, an informed recommendation on the afloat community's potential engagement in a VCoP can be made, including recommendations for communal development and sustainment. VCoP shall be defined as learning communities in which members are geographically separated and communicate primarily through either synchronous or asynchronous virtual forums (Dubé, Bourhis, \& Jacob, 2005; Liao, 2017; Wenger, McDermott, \& Snyder, 2002). The afloat community of the USCG shall refer to the operational component of the USCG in which members serve on board ships. Considering knowledge-sharing culture as members' perceptions of trust and reciprocity, disposition towards online learning, and willingness to share knowledge, the following research question guided this qualitative case study: How is the knowledge- sharing culture of the USCG's afloat community suited for VCoP engagement?

\section{Knowledge-Sharing in VCoP}

Successful VCoP are dependent upon effective knowledge-sharing between members (Lin, Hung, \& Chen, 2009; Usoro, Sharratt, Tsui, \& Shekhar, 2007). Knowledge-sharing in the workplace entails the professional exchange of information between two or more colleagues (Lin et al., 2009). The influences behind this exchange, however, are complex and multifaceted, particularly in rank-based hierarchical organizations. Research reveals that trust, reciprocity, and disposition towards online learning have a significant impact on members' willingness to exchange knowledge (Ardichvili, Page, \& Wentling, 2002; Lin et al., 2009; Usoro et al., 2007).

Communal trust and perceptions of others' integrity have a significant influence on members' willingness to exchange knowledge. Usoro et al. (2007) quantified trust in a virtual community according to the amount of integrity, benevolence, and shared professional competence that members expressed in themselves and others. Although integrity and the desire to serve the greater good are highly regarded tenets within the USCG's afloat community, perceptions of competence may be unduly influenced by the rank disparity. When studying a VCoP in the United States Air Force, Orhun and Hopple (2006) determined that perceived power imbalance negatively impacted knowledge- exchange between members. Given the organizational similarities between the USCG and USAF as armed services, the impact of trust on knowledge-sharing will be examined. In this study, trust will refer to members' comfort with sharing mistakes and lessons learned with other members.

Despite the lack of face-to-face interaction, VCoP members exchange knowledge in accordance with a commonly held set of social expectations (Lin et al., 2009). Social exchange theory espouses that individuals typically contribute the quantity and quality of actions that they anticipate receiving from others (Blau, 1964; Cheung, Lee, \& Lee, 2013). Knowledge reciprocity may significantly impact knowledge-sharing within the afloat community. In this study, knowledge reciprocity will refer to afloat members' perceptions regarding the balance of information exchanged between members.

\section{Willingness to Share Knowledge}

Effective knowledge-sharing, including the exchange of information between two or more learners, is essential to the development and sustainment of a CoP (Ku \& Fan, 2009; Lin et al., 2009). Depending on the community, knowledgesharing may occur in person or through virtual means. Regardless of the preferred communication forum, Ardichvili, Page, and Wentling (2003) described two elements of knowledge-sharing that must be fostered to maintain the flow of information between members: the desire to share knowledge and willingness to use the CoP as a source of knowledge. One's desire to share knowledge is influenced by trust, reciprocity, and the altruistic desire to contribute to the greater good (Ardichvili et al., 2003; Usoro et al., 2007). Specific to VCoP, learners' willingness to communicate in virtual forums and overall technical disposition are primary influences in the decision to share knowledge (Wang \& Haggerty, 2009). In order to foster a culture of knowledge-sharing, these "behavioral determinants" (Lin et al., 2009, p. 929) of knowledge exchange must be understood and developed. 
This is an author-produced, peer-reviewed version of this article. The final, definitive version of this document can be found online at TechTrends, published by Springer. Copyright restrictions may apply. doi: 10.1007/s11528-018-0291-8

\section{$\underline{\text { Trust }}$}

Trust entails a member's positive perceptions and confidence in the good intentions and reliability of community members (Lin et al., 2009). Trust is an abstract concept and challenging to define in an exclusive manner, but its presence in a VCoP and influence on knowledge-sharing is palpable. Ardichvili et al. (2003) delineated two types of trust critical to learning communities: knowledge-based trust and institution-based trust. Knowledge-based trust is established as members interact on a consistent basis and begin to understand what type of information, the degree of complexity, and the quality of contribution that they can expect from one another. Knowledge-based trust arises as individuals are able to manage their expectations and gain a greater sense of their role and the role of other members within the community (Ardichvili et al., 2003). Institution- based trust is established as participation in CoP becomes a normal standard of behavior. Ardichvili et al. (2003) noted that as members grow to expect organizational engagement and see all levels of their organization participate in knowledge-sharing, this behavior becomes the standard and members have confidence in the community. Frank et al. (2017) similarly related trust within an organization to the sense of belonging and consistency of members' contributions to a knowledge-sharing community. As members contribute regularly and witness the same extent of participation within the community, the behavior may be reinforced.

Usoro et al. (2007) considered trust to be the combination of three dimensions: competence, integrity, and benevolence. Trust, in concert with the integrity of the community, was determined to have the greatest impact on knowledge-sharing in Usoro et al.'s (2007) quantitative study. CoP members are more likely to share knowledge when they perceive their fellow members' intentions and contributions to the community to be valid and truthful. Additionally, knowledge-sharing is positively impacted when members feel comfortable sharing their questions and revealing the true extent of their knowledge with others (Yao, Tsai, \& Fang, 2015). Overall personal comfort with one's professional competence and faith in the benevolence and respect of other community members is critical to establishing trust and increasing the flow of knowledge within one's community. Trust has also been linked to greater levels of collaboration within communal learning environments (Chang, 2017).

\section{Knowledge Reciprocity}

When community members perceive the contributions of other members to be commensurate with their own, they are more likely to reciprocate these actions. Reciprocity, in accordance with social exchange theory, implies that CoP members return the knowledge and benefits that they receive from others (Blau, 1964; Cheung et al., 2013; Lin et al., 2009;). Understanding the potential negative impacts of reciprocity is critical to communal longevity. When members do not believe that their knowledge is valued or that the intentions of other members of the community are positive, their contributions may be reduced. Lin et al. (2009) determined that communal reciprocity was more closely related to trust and self-efficacy than knowledge-sharing, but its potential impact on members' willingness to engage with others and, ultimately, communal longevity should be considered.

Similar to the influence of reciprocity, members may possess a moral obligation to share knowledge. Knowledgesharing is positively impacted by members' altruistic desire to help others (Wasko \& Faraj, 2000). In public sector communities, the desire to contribute to the greater good is directly aligned with organizational objectives geared towards service or humanitarian goals (Camilleri \& Van Der Heijden, 2007). Communal altruism may also be the result of the "been there, done that" (Wasko \& Faraj, 2000, p. 168) mentality whereby one's personal experience motivates him to provide others with the knowledge he deemed valuable in a particular situation.

\section{Disposition Towards Online Learning}

The technical infrastructure of VCoP requires members to have some degree of technical capability and comfort with virtual communications. Wang and Haggerty (2009) advocated that learners possess virtual competence, self-efficacy, and social skills in order to participate in virtual community of practice. Self-efficacy refers to an individual's confidence and comfort with communicating in a virtual forum (Wang \& Haggerty, 2009). Wang and Haggerty (2009) defined virtual competence as the "ability to apply the same technology to different extents in various scenarios" (p. 579). Competence has an impact on virtual social skills, whereby individuals built relationships using virtual forums. These relationships are the product of capability and confidence within the VCoP and are critical to knowledge sharing and communication. 
This is an author-produced, peer-reviewed version of this article. The final, definitive version of this document can be found online at TechTrends, published by Springer. Copyright restrictions may apply. doi: 10.1007/s11528-018-0291-8

Unlike a traditional face-to-face community, VCoP require members to adapt alternative communication mechanisms and procedures. The geographic segregation and unique operating schedules of USCG ships support the use of virtual communications such as email. Similar users' needs contributed to the success of the United States Army's (USA) VCoP, Company Command, which connected field users with legacy knowledge and operational experience critical to mission success (Dixon et al., 2005). Despite the potential flexibility and utility of virtual learning, afloat members' disposition towards online learning may not align with virtual communication preferences. To ensure that members are able to successfully employ their community's virtual tools, advance research and analysis should be conducted to assess the capabilities of learners and their virtual networks (Dubé et al., 2005). In this study, disposition towards online learning refers to afloat members' desire and comfort with sharing knowledge in a virtual forum.

This literature review supports the notion that the afloat community's unique operational demands and geographic segregation make it a prime candidate for development and engagement in a VCoP. Existing research also reveals potential challenges that the community may face regarding trust and knowledge-sharing due to conflicting opinions on virtual forums and concerns regarding professional reputation and potential vulnerability. Anecdotal experience affirms the need for additional professional development opportunities and engagement as well as the presence of communal reservation surrounding virtual knowledge exchange. However, additional research is required to understand the knowledge-sharing culture of the USCG's afloat community.

\section{Methodology}

A qualitative case study was employed to facilitate in-depth analysis of knowledge-sharing trends within the afloat community and their compatibility with current research on knowledge-sharing trends within successful VCoP. The single qualitative case study is exploratory in nature and is recommended for researchers gaining access to a case not previously explored through empirical research (Creswell, 2013; 2014; Yin, 2014). The afloat community constituted a single case whose knowledge-sharing culture was explored through semi-structured interviews of six members (four males, two females) with varying degrees of time in service and afloat time. All members were commissioned officers stationed at USCG Headquarters in Washington, DC.

Purposeful sampling was used to capture opinions of members with diverse levels of afloat experience and total time in the USCG. Members' total time in service ranged from 2.5 years to 19 years. Sea time ranged from 1 year to 9.5 years. Members were asked to participate based on their relative amount of sea time and time in service to ensure that a diverse amount of experience and seniority was reflected in the data collection process. An email invitation was sent to members based on their relative experience level as approximated by the researcher.

One researcher conducted the one-on-one semi-structured interviews. Participants signed consent forms, including one copy for their records and one copy for the researcher that was retained in a secure space. Interviews were conducted behind closed doors in a conference room at USCG Headquarters to facilitate privacy. Interviews lasted between 15 and 45 minutes, and participants were asked questions grouped according to the elements of knowledgesharing with which they align (Appendix A). Follow-up questions were asked during the interview as needed to clarify responses or further explore opinions presented by members. The interviews were digitally recorded (with members' knowledge and consent) and then transcribed by the researcher.

Interview responses were examined using the constant-comparative approach (Boeije, 2002; Glaser \& Strauss, 1967; Lincoln \& Guba, 1985). As advocated by Glaser and Strauss (1967), the researcher engaged in constant comparison by analyzing, coding, and consistently integrating codes within and between participant responses. Extensive memoing was employed when reviewing interview transcriptions to capture the researcher's thoughts on coding and categorization of data in a timely manner as themes emerged (Glaser \& Strauss, 1967). Similar to Miles, Huberman, and Saldaña's (2014) perceptions of "jotting” notes, memos provided the researcher with a mechanism for taking an inventory of data collected, analyzed and categorized at different points in the research process.

The comparative analysis of interview data occurred in a layered approach, whereby interview data was initially reviewed independently. Boeije (2002) recommended a systematic approach to analyzing interview data in which comparisons are first made within a single interview response. The researcher reviewed individual interviews to get a sense of consistency and commonalities within each participant's statement and assigned corresponding codes outlined in Table 1. Interview responses were then compared between participants to further define patterns and connect codes as themes emerged (Boeije, 2002). Themes were compared to the literature on VCoP development to 
This is an author-produced, peer-reviewed version of this article. The final, definitive version of this document can be found online at TechTrends, published by Springer. Copyright restrictions may apply. doi: 10.1007/s11528-018-0291-8

enable thorough interpretation of findings and further categorization of data (Creswell, 2013; Merriam, 2009). Table 2 illustrates the recurrent themes and categorization of findings from the interview response comparison. Categories for comparison were developed based upon the concentration areas within the main research question, including knowledge-sharing willingness and influences, trust, and disposition towards online learning. Perceptions of communal competence were also compared to qualify the relationship between trust and professional competence and the nature of existing afloat professional development opportunities.

By comparing different participant responses and emergent themes, the researcher established a rich description of participants' perceptions of the afloat community's knowledge-sharing culture. To effectively conceptualize and classify the findings, recurrent interview themes in Table 2 were clustered and classified (Boeije, 2002). Final classifications combined recurrent themes surrounding the quantity and quality of knowledge-shared, influences in the decision to share knowledge, and perceptions of virtual knowledge exchange. The resultant major themes included (1) members' confidence in overall knowledge-sharing, (2) the influence of service reputation and subject matter in one's decision to share knowledge, and (3) overall willingness to share some types of knowledge virtually with a provision for anonymity.

\section{Results}

\section{Confidence in Knowledge-Sharing}

All members expressed confidence in the afloat community's willingness to share knowledge. One member described the afloat community as "tight knit" and considered the exchange of sea stories, or anecdotal experience, to be a central tenet of the afloat community. One of the primary themes regarding knowledge-sharing, however, involved the influence of subject matter in afloat members' decision to share knowledge. Several members distinguished between operational knowledge and professional development knowledge. Operational knowledge was determined to be information regarding area- specific operations, qualifications, or patrol summaries. One member described this knowledge as "port call specific," and differentiated this type of geographic and logistical knowledge from that of professional development. Members considered professional development knowledge to be a less formal type of knowledge, referring to this as "knowledge you need to get the job done" or "best practices" and "lessons learned."

There was consensus throughout members' responses that the USCG does provide an adequate amount of formal instruction for teaching operational knowledge. One member noted, "I think that one of the best mediums we have in the Coast Guard is PCO/PXO [Prospective Commanding Officer/Prospective Executive Officer] school. I think people are very willing to share there...I found that forum was super valuable and that everyone was very comfortable.” PCO/PXO school refers to formal professional training members attend prior to assuming the role of Commanding Officer (CO), first in charge, or Executive Officer (XO), second in charge, on a ship. Another member considered the sharing of information, whether operational or professional development- related, to be "very sporadic" and frequently lost over time as members transfer from units and the knowledge-base changes. This member did, however, emphasize that formal schools are an effective mechanism for operational knowledge and also expressed confidence in overall willingness to share knowledge in a formal, professional environment.

When asked their perceptions of sharing professional development knowledge, or knowledge of mistakes or lessons learned, members' opinions were less consistent. Some members felt that they were willing to share their mistakes or lessons learned based on their relative amount of sea time and overall time in service. One member noted, "I'm fairly open...but I guess I can see people as they get more senior in the Coast Guard not wanting people seeing all their mess ups when they were younger." Another member considered seniority to positively contribute to the amount of knowledge shared. This individual noted that he was more willing to share professional development knowledge at a more senior level and explained that "from the bad, there is a lot of good to be gained because I did struggle that first year...I want to tell members of our community that you can rise above.” Other members considered sharing information regarding mistakes and lessons learned dangerous to their service reputation, and an overall inhibitor to the amount of knowledge exchanged within the afloat community. 
This is an author-produced, peer-reviewed version of this article. The final, definitive version of this document can be found online at TechTrends, published by Springer. Copyright restrictions may apply. doi: 10.1007/s11528-018-0291-8

\section{Knowledge-Sharing and Service Reputation}

Noting that some members of the afloat community are more "risk-averse," one member highlighted "professional vulnerability" as preventing individuals from sharing or reciprocating knowledge shared by others regarding mistakes or lessons learned. Several members referred to the afloat community's reputation for "eating its young" and considered this type of negativity and hypersensitivity surrounding service reputation to prevent open exchange of mistakes or lessons learned. One member noted, "I would definitely feel comfortable sharing something that went well over something that didn't go well, but it depends on the situation." The member went on to note that the decision to share knowledge would only be made after consideration of "what the risks are to my personal reputation."

All members noted concern regarding sharing of professional development knowledge, specifically regarding their own lessons learned and mistakes. They also considered this reluctance to be shared throughout the community. Two members specifically referenced a lack of tolerance for mistakes in the afloat world with one individual further detailing a "zero forgiveness mentality in the fleet... when sometimes things don't work out, we don't want to shed any more light on that path." These opinions support the notion that reciprocity is negatively impacted when members are less willing to engage. As Lin et al. (2009) cautioned, knowledge-sharing is not reciprocated when members have doubts regarding the communal value of their knowledge. Although reputation and vulnerability may threaten reciprocity, members did express the belief that professional knowledge, even when it involves mistakes and potential vulnerabilities, benefits the greater community. This finding supports the concept of altruism, which Wasko \& Faraj (2000) considered a key contributor to knowledge-sharing.

\section{Influence of Subject Matter on Knowledge-Sharing}

Members expressed concern with sharing their mistakes, but they also noted that this knowledge is valued by other members. Five out of six members believed that professional development knowledge involving mistakes is valued by other members of the community and that the community learns from this type of knowledge-exchange. One member considered the exchange of sea stories about mistakes and challenges an integral component of the afloat community and noted, "I have a tendency to turn it into a foible where I can look at it with a sense of humor and maybe not take it quite so much as a personal failure." Another member stated that knowledge shared about lessons learned is respected because "it's all for learning because we all make silly mistakes." Although members continued to differentiate between professional development and operational knowledge when discussing communal value, they considered both types of knowledge exchange valuable. One member praised the afloat community's information exchange, noting "I think the afloat community is really good about listening especially about operational experiences...I think people listen to that because it's a little bit more high stakes and then try to get as much information as possible.” This member's comment draws a connection between the value of knowledge and its potential impact on operations. Ultimately, this member believes that knowledge exchange is valued based upon its potential operational impact. The member's comment also supports the notion that the afloat community has faith in the positive intention of others and supports the existence of communal benevolence.

The member who did not consider knowledge-sharing about mistakes to be valued within the community stated that this perception might be related more to individual experience and personality. The member stated, "It [appreciation] is based on the person. I've never felt a fear of retribution, but sometimes when you share a criticism of the afloat community, someone may take it personally... and think that it's a problem with me and not with the afloat community in general." The member's reference to retribution relates to the presence of integrity and benevolence within the afloat community. This individual did not see value in sharing mistakes but considered this lack of value related to personalities versus communal perceptions. This contention, although contrary to that of other members regarding knowledge value, supports the notion that the afloat community possesses benevolence and integrity. Benevolence and integrity are key contributors to communal trust and effective knowledge-sharing (Usoro et al., 2007). When comparing members' responses regarding the afloat community's willingness to exchange knowledge, members were willing to share knowledge and felt that all types of knowledge exchange were valuable. Members did, however, express concern that their service reputation could be negatively impacted as a result of sharing information on mistakes or lessons learned. This contradiction implies that integrity and honesty regarding information exchange may be impacted by the type of knowledge being shared, particularly if this knowledge involves an error or lesson learned. 
This is an author-produced, peer-reviewed version of this article. The final, definitive version of this document can be found online at TechTrends, published by Springer. Copyright restrictions may apply. doi: 10.1007/s11528-018-0291-8

\section{Disposition and Preference for Virtual Communication}

When asked what communication forum afloat members most frequently employed, email and face-to-face were referenced by all respondents. One member did discuss the use of the USCG online portal as a "knowledge repository" and further clarified that "SharePoint" is a similar online information repository that could be used to save and share communal knowledge if more members took the time to learn how to successfully employ the tool. This member did, however, emphasize that tools such as SharePoint and the portal are not necessarily the right medium for sharing professional development knowledge. The member explained, "Yeah, I don't know if that [virtual forum] is where I would seek out info if I'm having this personal counseling session and I don't know if I would seek out info on how to do a counseling session." The member emphasized that professional development knowledge is personal and that members may not want to share things virtually if they perceive "risks to their reputation.” Thus, although this member considered virtual forums valuable sources of professional knowledge and preferred to employ these forums when possible, the member's willingness to share knowledge was influenced by concerns regarding service reputation.

When discussing preferences for communication and willingness to share knowledge virtually, the desire for anonymity was expressed. One member stated:

I think it would be helpful to have something like that [virtual forum]...I think that we need a mechanism to do it that's non retribution and, of course, there will be judgment in there, but you can't judge the particular person by name. If you were to have a mechanism available like that, people might be willing to put their toe in the water.

Three members noted that anonymity would be helpful and would potentially provide "protection from scrutiny and...preserve career viability." Anonymity has the potential to positively influence both willingness to share knowledge and members' disposition towards online learning.

All members affirmed their willingness and their belief in the willingness of the afloat community to share knowledge in a virtual forum. One member noted that age may play a factor in some individuals' decisions to engage in knowledge-sharing virtually. Specifically, this individual's experience influenced the belief that older members may be less willing to use virtual communication forums. The member explained, "My last CO [Commanding Officer] was warrant to lieutenant...he was not receptive to doing things electronically and sometimes even getting electronic signatures on things was like pulling teeth, but those are anomalies now in the fleet." This was the only member that referenced concerns regarding age negatively influencing one's disposition towards online learning. Interestingly, the two more senior members of the group of six respondents noted that their willingness to communicate virtually had increased over time. One member described a personal blog that the individual kept and affirmed overall comfort level with blogging about topics that did not involve "legal matters" or political statements. The other member made a powerful statement about disposition towards sharing knowledge virtually with the greater afloat community:

Before...I had a little more apprehension in a virtual forum like that, but now I'm focusing on the job I have at hand and because I am of the belief that the paradigm changes at some point and we're all in this together and if we don't make this appealing and give that sense of brother and sisterhood of being afloat then no one will want to do it because who wants to be away 185 days a year and be miserable? It takes that pioneer or that groundbreaker to kind of get in there and get their marker in the game.

This statement reflected a sense of benevolence and trust on the members' behalf, whereby contributing knowledge was viewed as necessary to sustain the greater community and to generate a greater sense of camaraderie. This individual had the second greatest amount of sea time within the respondent group and intended to continue to serve aboard ships until retirement. Further interviews with members of the afloat community are required to validate whether this opinion regarding virtual communication and willingness to exchange knowledge is shared at the higher ranks of the afloat community.

\section{Discussion and Conclusion}

The purpose of this pilot study was to make an informed recommendation on how the knowledge-sharing culture of the USCG's afloat community is suited for VCoP engagement. Although members expressed an overall willingness to share knowledge and positive disposition towards online learning, perceptions of trust may pose a challenge to effective knowledge-sharing. Institution-based and knowledge-based trust are dependent upon consistent information 
This is an author-produced, peer-reviewed version of this article. The final, definitive version of this document can be found online at TechTrends, published by Springer. Copyright restrictions may apply. doi: 10.1007/s11528-018-0291-8

exchange between members (Ardichvili et al., 2003). Similarly, knowledge reciprocity is dependent upon members' perceptions of balanced information sharing (Lin et al., 2009). Methods to increase members' comfort sharing professional information may enhance communal trust. Respondents offered recommendations regarding the use of anonymity to foster greater comfort expressing mistakes and lessons learned, but lingering concerns regarding judgment and impaired service-reputation may limit knowledge-sharing.

Participants expressed a high degree of trust in the importance and value of knowledge-sharing in the afloat community. Members agreed that knowledge was shared consistently, but expressed concerns regarding the impact of knowledge-sharing on service reputation and the need for anonymity when sharing knowledge. Somewhat paradoxically, members expressed a belief in knowledge-sharing as essential to assisting the greater good, but felt that other members of the community may judge their disclosures regarding mistakes and lessons learned. Further research is necessary to determine whether this fear of judgment and its limitation of knowledge exchange is a function of rank disparity as in Orhun and Hopple's (2006) study of a virtual community in the USAF. As one member noted, sharing knowledge is "all about helping others," but concerns regarding judgment and negative career implications were evident throughout interviews with respondents. In addition to exploring online forums compatible with the USCG's information technology infrastructure, provisions for anonymity will also be examined. Specifically, mechanisms in which members can contribute to the group without revealing their identity will be considered, along with any organizational or privacy concerns that may arise through anonymous knowledge contributions.

In this study, trust included elements of integrity, benevolence, and perceptions of professional competence. Members’ concerns regarding the vulnerability of their professional reputations and desire to preserve positive perceptions of competence may limit engagement in honest, productive discourse. Overall positive perceptions of communal professionalism and members' desires to serve and assist the greater good, however, may help overcome fears regarding service reputation. Promoting fruitful, abundant discourse regarding professional operational knowledge may not be as difficult as promoting the honest exchange of mistakes and lessons learned. Unfortunately, operational knowledge alone will not fill the professional development void that several members expressed. This pilot study revealed that the afloat community possesses interest and potential for VCoP development, but mechanisms to enhance trust should be further explored.

The next iteration of this study will concentrate on how to foster open discourse and overcome concerns regarding personal and professional judgment. Specifically, the influence of anonymity on knowledge exchange will be explored. The findings from this study may also inform future learner analyses in support of advanced distributed learning and human systems integration strategies for major acquisitions. This pilot study affirmed the notion that VCoP are worth pursuing for this small operational community and that afloat members are, in fact, committed to enhancing knowledge-exchange for communal benefit.

Ethical Approval: All procedures performed in studies involving human participants were in accordance with the ethical standards of the institutional and/or national research committee and with the 1964 Helsinki declaration and its later amendments or comparable ethical standards.

Informed Consent: Informed consent was obtained from all individual participants included in the study.

\section{References}

Ardichvili, A., Page, V., \& Wentling, T. (2003). Motivation and barriers to participation in virtual knowledgesharing communities of practice. Journal of Knowledge Management, 7(1), 64-77.

Blau, P. M. (1964). Exchange and power in social life. New York, NY: J. Wiley.

Boeije, H. (2002). A purposeful approach to the constant comparative method in the analysis of qualitative interviews. Quality and Quantity: International Journal of Methodology, 36(4), 391-409.

Camilleri, E., \& Van Der Heijden, B. I. J. M. (2007). Organizational commitment, public service motivation, and performance within the public sector. Public Performance and Management Review, 31(2), 241-274.

Chang, W. L. (2017). Online training for business plan writing through the World Café method: The roles of leadership and trust. Universal Access in the Information Society: International Journal, 16(2), 313-324. doi: 10.1007/s10209-016-0459-y 
This is an author-produced, peer-reviewed version of this article. The final, definitive version of this document can be found online at TechTrends, published by Springer. Copyright restrictions may apply. doi: 10.1007/s11528-018-0291-8

Cheung, C. M. K., Lee, M. K. O., \& Lee, Z. W. Y. (2013). Understanding the continuance intention of knowledge sharing in online communities of practice through the post-knowledge-sharing evaluation processes. Journal of the American Society for Information Science and Technology, 64(7), 1357-1374. doi:10.1002/asi.22854

Creswell, J. W. (2013). Qualitative inquiry and research design: Choosing from among five approaches, (3rd ed.) Los Angeles, CA: Sage Publications.

Creswell, J. W. (2014). Educational research: Planning, conducting, and evaluating quantitative and qualitative Research (5th ed.). Boston, MA: Pearson.

Dixon, N., Allen, N., Burgess, T., Kilner, P., \& Schweitzer, S. (2005). Company Command: Unleashing the power of the Army profession. West Point, NY: Center for the Advancement of Leader Development \& Organizational Learning.

Dubé, L., Bourhis, A., \& Jacob, R. (2005). The impact of structuring characteristics on the launching of virtual communities of practice. Journal of Organizational Change Management, 18(2), 145-166.

Frank, A. G., Sander, N., Gastaldi, L., Madini, E., \& Corso, M. (2017). An assessment model for virtual communities of practice: A study in the oil and gas industry. Knowledge Management Research \& Practice, 15(4), 507-522. doi: 10.1057/s41275-017-0074-6

Glaser, B. G., \& Strauss, A. L. (1967). The Discovery of Grounded Theory: Strategies for Qualitative Research. Chicago, IL: Aldine.

Ho, K., Jarvis-Selinger, S., Norman, C. D., Li, L. C., Olatunbosun, T., Cressman, C., \& Nguyen, A. (2010). Electronic communities of practice: Guidelines from a project. Journal of Continuing Education in the Health Professions, 30(2), 139- 143. doi: 10.1002/chp.20071

Kok, A. (2010). Demystifying virtual communities of practice: A case study of IBM. Turkish Online Journal of Distance Education, 11(2), 119-128.

Ku, E. C. S., \& Fan, Y. W. (2009). Knowledge sharing and customer relationship management in the travel service alliances. Total Quality Management \& Business Excellence, 20(12), 1407-1421.

Liao, T. H. (2017). Developing an antecedent model of knowledge sharing intention in virtual communities. Universal Access in the Information Society: International Journal, 16(1), 215-224. doi: 10.1007/s10209016-0452-5

Lin, M.-J. J., Hung, S.-W., \& Chen, C. J. (2009). Fostering the determinants of knowledge sharing in professional virtual communities. Computers in Human Behavior, 25(4), 929-939. doi:10.1016/j.chb.2009.03.008

Lincoln, Y. S., \& Guba, E. G. (1985). Naturalistic inquiry. Beverly Hills, CA: Sage Publications.

Merriam, S. B. (2009). Qualitative research: A guide to design and implementation. San Francisco, CA: JosseyBass.

Miles, M. B., Huberman, A. M., \& Saldaña, J. (2014). Qualitative data analysis: A methods sourcebook. Thousand Oaks, CA: Sage publications.

Orhun, E., \& Hopple, J. (2006). Factors influencing knowledge sharing in the financial management community of practice of the USAF portal. Proceedings of the American Society for Information Science and Technology, 43(1), 1-15. doi: 10.1002/meet.14504301319

Rossett, A., \& Mohr, E. (2004). Special issue e-learning - performance support tools: Where learning, work, and results converge - Einstein was an early performance support tool user. The U.S. Coast Guard uses PSTs. Time to get on board? T+d: Better Performance Through Workplace Learning, 58(2), 35-39

Salas, E., Milham, L. M., \& Bowers, C. A. (2003). Training evaluation in the military: Misconceptions, opportunities, and challenges. Military Psychology, 15(1), 3-16.

Usoro, A., Sharratt, M. W., Tsui, E., \& Shekhar, S. (2007). Trust as an antecedent to knowledge sharing in virtual communities of practice. Knowledge Management Research and Practice, 5(3), 199-212.

Wang, Y., \& Haggerty, N. (2009). Knowledge transfer in virtual settings: The role of individual virtual competency. Information Systems Journal, 19(6), 571-593. doi: 10.1111/j.1365-2008.00318.x

Wasko, M. M., \& Faraj, S. (2000). "It is what one does": Why people participate and help others in electronic communities of practice. The Journal of Strategic Information Systems, 9(2), 155-173. doi: 10.1016/S09638687(00)00045-7

Wenger, E., McDermott, R. A., \& Snyder, W. (2002). Cultivating communities of practice: A guide to managing knowledge. Boston, MA: Harvard Business School Press.

Yao, C. Y., Tsai, C. C., \& Fang, Y. C. (2015). Understanding social capital, team learning, members' e-loyalty and knowledge sharing in virtual communities. Total Quality Management \& Business Excellence, 26, 619-631. doi:10.1080/14783363.2013.865918

Yin, R. K. (2014). Case study research: Design and methods (5th ed.). Thousand Oaks, CA: Sage. 
This is an author-produced, peer-reviewed version of this article. The final, definitive version of this document can be found online at

TechTrends, published by Springer. Copyright restrictions may apply. doi: 10.1007/s11528-018-0291-8

\section{Appendix A. Interview Questions}

\section{$\underline{\text { Total Service and Afloat Time }}$}

1. How many years of service in the U.S. Coast Guard (USCG) do you have? How many years of sea time have you served in the USCG?

Knowledge Reciprocity and Willingness to Share Knowledge

2. Do you believe that members of the afloat community share knowledge frequently with other members of the afloat community?

a. If so, how does this knowledge-sharing occur?

b. If not, why do you think that knowledge is not shared between members of the afloat community?

3. Are you comfortable sharing mistakes and lessons learned with other members of the afloat community?

a. If not, why?

Trust: Integrity and Benevolence

4. Do you trust other members of the afloat community will respect knowledge shared regarding mistakes or lessons learned?

a. If not, why?

Trust: Professional Competence

5. Do you perceive a need for additional professional development opportunities for the afloat community?

Disposition Towards Online Learning

6. Are you comfortable sharing knowledge in a virtual forum (blog post, online classroom, etc.)?

a. Do you perceive that other members of the afloat community are comfortable sharing knowledge in a virtual forum?

b. If not, why? 